\title{
Review of Kristina Schönfeldt (ed.), The Arctic in International Law and Policy
}

Kristina Schönfeldt (ed.). The Arctic in International Law and Policy (Documents in International Law series). Hart Publishing, Oxford and Portland, Oregon. 2017. 1680 pages, ISBN 9781509915798.

"Excitement" and "anticipation" are not words that one normally associates with opening and perusing a collection of documents in international law; but those are exactly the words that I already associate with the valuable compilation The Arctic in International Law and Policy. I have worked on arctic legal issues on and off since the late 1970s and as a result have my own small collection of arctic legal and policy documents both electronically and in hard copy scattered around various projectrelated files in my office. My collection is haphazard; it is neither systematic nor complete, and I am sure that I have multiple copies of the same documents in different places. It may be a little over the top to say that this volume will transform my life, but it will certainly transform my workspace because I now have at my fingertips a comprehensive, well-organized, accessible and well-indexed collection of the most important documents pertaining to arctic law and policy in the English language. This is no mean feat. There is, however, one important qualification which is no fault of Schönfeldt's; in some cases the "owner" of the document in question has not given permission for the document to be reproduced. The first example of this is found in Part 2 "Arctic Cooperation" under the first heading "Arctic Council". One might reasonably expect this to be a lengthy section, but the Arctic Council apparently has not granted permission to have the relevant documents reproduced. Schönfeldt's response is to maintain a placeholder entry and to provide a url where the relevant document(s) can be found. This reticence on the part of the Arctic Council may be a mixed blessing. While it would have been nice to have had all of the relevant documents in a single place, one can only assume that had the Council been more forthcoming this already large volume would be much, much larger, or perhaps two!

`Correspondence to: ndbankes@ucalgary.ca

(C) 2018 N. Bankes. This is an Open Access article distributed under the terms of the Creative Commons AttributionNonCommercial 4.0 International License (https://creativecommons.org/licenses/by-nc/4.0/), allowing third parties to share their work (copy, distribute, transmit) and to adapt it, under the condition that the authors are given credit, that the work is not used for commercial purposes, and that in the event of reuse or distribution, the terms of this license are made clear.

Citation: Nigel Bankes. "Review of Kristina Schönfeldt (ed.), The Arctic in International Law and Policy" Arctic Review on Law 
This volume is, as far as I know, the first such collection of circumpolar Arctic legal materials. But as Schönfeldt herself acknowledges, there are a few national collections in existence, including a collection of historical documents on the Arctic published in 2016 by Global Affairs Canada under the meticulous editorship of Janice Cavell. ${ }^{1}$

The Arctic in International Law and Policy comprises a 64 page analytical introduction, a chronology of (legally) significant events and a collection of documents organized into ten parts. Document entries are sequentially numbered (364 in total).

The analytical introduction commences with two brief entries on "the legal framework" and "Arctic definitions, geography and ecosystem" before providing short accounts of the collection of documents found in each of the subsequent ten sections. These short accounts are useful not only for the way they provide a linking narrative and context for the collection, but also for the extensive references made to secondary literature. In some respects, these accounts function as an annotated bibliography accompanying the document collection.

Part 1, "Arctic Policy", comprises a collection of key national policy documents on the arctic policies of Arctic states, as well as a selection of policy documents from selected non-Arctic states (China, Germany, Korea, Singapore, Japan, Italy) and other actors (the EU). In this Part, Schönfeldt provides key historical documents, as well as the most recent statements of national (and EU) Arctic policies. Part 2, entitled "Arctic Cooperation" contains one section on multilateral cooperation: the Arctic Council, the Barents Euro-Arctic Council and the Northern Dimension, a Finnish initiative designed to bridge the EU, Russia and the Baltic Sea regions, ${ }^{2}$ and one section on bilateral cooperation. The section on multilateral cooperation provides, as noted above, the first reference to documents not included because permission to reproduce was not forthcoming from the Artic Council. My only comment in this instance is that it might have been more helpful if Schönfeldt had provided a list of the documents that she would have selected for reproduction. As it stands, there is simply a reference to "Arctic Council Declarations". Parenthetically I note that the Arctic Council does have available on its website a fully searchable compilation of all Arctic Council declarations from 1996 (Iqaluit) to 2017 (Fairbanks). ${ }^{3}$ The sub-section on bilateral cooperation is relatively short and one senses that Schönfeldt must have been highly selective here.

Part 3, entitled "Maritime Zones", provides law of the sea related legislation for each of the five Arctic Coastal States and in some cases (e.g. Canada) provides examples of diplomatic exchanges between the coastal state and other states with respect to maritime zones. Part 4 is a collection of maritime delimitation agreements between Arctic coastal states. This includes at least one agreement which I do not believe has been made available in English before. This is (Document 130, page 726) a 2007 Agreement between the Government of Iceland and the Kingdom of Denmark and the Regional Government of the Faroe Islands on the Maritime Boundary in the Area Between the Faroe Islands and Iceland. Part 5 collects national submissions from four of the Arctic coastal states (excluding the United States since the United States is not a party to the Law of the Sea Convention) to the Commission on the 
limits of the continental shelf. It also includes Notes Verbale from other states with respect to those submissions, as well as the Commission's recommendations with respect to Norway's submission and Denmark's partial submission.

Part 6 deals with "Arctic Shipping". The focus here is principally on the relevant IMO instruments (including the Polar Code) as well as the Arctic SARS Agreement (Agreement on Cooperation on Aeronautical and Maritime Search and Rescue in the Arctic). A possible addition here (if available) might have been the recommendations of the Arctic Council's Arctic Marine Shipping Assessment. ${ }^{4}$

Part 7 offers coverage of multilateral and bilateral fisheries agreements relevant to the Arctic, as well as some national documents. These documents include summary statements of meetings of the five arctic coastal states and some diplomatic correspondence related to Canada's enforcement actions in the NAFO regulatory area beyond Canada's Exclusive Economic Zone, which ultimately led to the Fisheries Furisdiction Case (Spain v Canada) before the International Court of Justice. ${ }^{5}$ A discussion of these instruments in the analytical introduction (at lix - lxvii) is especially useful. The next edition will need to include the recently adopted International Agreement on the Prevention of Unregulated Fishing in the High Seas of the Central Arctic Ocean. ${ }^{6}$

Part 8, one of the longest, provides a collection of documents concerning protection of the Arctic environment. This part is divided into two main sections: international instruments, and miscellaneous policy documents and national instruments. The section on international instruments is further subdivided into instruments dealing with: (1) the general marine (sic) environment (including multilateral instruments such as the 1991 Arctic Environmental Protection Strategy, the OSPAR Convention (the Convention for the Protection of the Marine Environment of the North East Atlantic), the NAMMCO Agreement (the Agreement on Cooperation in Research, Conservation and Management of Marine Mammals) and the Nordic Environmental Protection Convention, as well as bilateral agreements such as the Canada/Denmark Agreement of 1983 on Cooperation Relating to the Marine Environment), (2) instruments relating to biodiversity (with material dealing with polar bears, seals, whales, caribou, and birds) and (3) agreements and instruments relating to marine oil pollution and airborne pollution. Once again, Arctic Council documents dealing with oil pollution and black carbon and methane are included only by way of reference to their titles and urls. The miscellaneous/national instruments section truly is miscellaneous. It includes resolutions dealing with cooperation between different international secretariats (e.g. the Arctic Council's working group on the Conservation of Arctic Flora and Fauna (CAFF) and the Convention on Biological Diversity), diplomatic correspondence (especially with respect to Canada's Arctic Waters Pollution Prevention Act in the 1970s and Canada's NORDREGG regulations) and IMO materials. I think that this section might have benefited from some subheadings to guide the reader reviewing the table of contents. 
Part 9 deals with the protection of arctic indigenous peoples. This part includes historical material such as the famous Lapp Codicil of 1751 as well as more recent instruments such as the 2008 draft of the proposed Nordic Saami Convention.

Part 10 is entitled "Arctic Disputes" and contains sections dealing with the Northwest Passage, the Northern Sea Route, the Svalbard Archipelago, Hans Island (between Greenland and Canada), the Sverdrup Islands (the historical dispute in the 1920s/1930s between Norway and Canada), the Bering Sea and the Beaufort Sea. Much of the material here consists of diplomatic correspondence.

Schönfeldt concludes her analytical introduction with an eloquent "Outlook" in which she expresses (at xcvii) the "certainty that the Arctic region will continue its transformative change". I think that we can also anticipate that the regulatory architecture for the Arctic will need to be responsive and adapt.

Inevitably, a reviewer must ask himself or herself whether there are important omissions in the work under review. This is not the case with The Arctic in International Law and Policy. Whereas there are documents that I might like to have seen included (such as the bilateral reindeer agreements between Norway and Sweden ${ }^{7}$ and Norway and Finland ${ }^{8}$ to complement the historical Lapp Codicil), these wishes simply reflect personal interest rather than important omissions. I do, however, have a couple of picky points. For example, the section on whales in Part 8 reproduces the International Convention for the Regulation of Whaling (page 1212) but not the Schedule (which contains inter alia the aboriginal subsistence exception); similarly, while the section on polar bears in the same part reproduces (page 1170) the 1973 regional agreement, it might have been useful to have added Canada's interpretive declaration, which deals with indigenous communities' rights to continued harvest. But these are minor points.

My one practical concern is whether the volume will stand up to the heavy use which good document collections are inevitably subjected to. Time will tell. Perhaps the answer will simply be successive new editions, although in the first instance I would prefer to see a supplementary volume - if only to reduce the cost of acquisition.

My overall message, if it is not already clear, is that all arctic legal scholars should have a personal copy of this volume on their shelves. The volume will also be invaluable to anyone who teaches an arctic law or policy course, although there is far more material here than one could cover in a single course. Schönfeldt deserves our thanks and congratulations for her achievement.

Nigel Bankes 
Review of Kristina Schönfeldt (ed.), The Arctic in International Law and Policy

\section{Notes}

1 Janice Cavell (ed.), Documents on Canadian External Relations, The Arctic 1874 - 1949, Global Affairs Canada (2016).

2 Analytical introduction, at xlvi.

3 All Arctic Council Declarations 1996 - 2017 (101 pp.) <https://oaarchive.arctic-council.org/ handle/11374/94>.

4 AMSA, available here https://pame.is/index.php/projects/arctic-marine-shipping/amsa Schönfeldt discusses the AMSA in her analytical introduction (at lvii).

51998 ICJ Reports 432 (Jurisdiction of the Court).

6 Adopted in Washington DC, November 30, 2017, text not yet publicly available.

7 See, for example, Agreement between Sweden and Norway on the grazing of reindeer (with annexed maps, and with exchange of letters dated 28 April 1972), Oslo, 9 February 1972, 969 UNTS 44.

8 See for example Agreement between the Republic of Finland and the Kingdom of Norway on the construction and maintenance of reindeer fences and on other measures to prevent reindeer from entering the territory of the other country, Karasjok, 9 December 2014, UNTS \# 54172 available on line https:// treaties.un.org/doc/Publication/UNTS/No\%20Volume/54172/Part/I-54172-080000028049cad6.pdf 